Hydrol. Earth Syst. Sci., 17, 3389-3395, 2013

www.hydrol-earth-syst-sci.net/17/3389/2013/

doi:10.5194/hess-17-3389-2013

(C) Author(s) 2013. CC Attribution 3.0 License.

\title{
Technical Note: A comparison of model and empirical measures of catchment-scale effective energy and mass transfer
}

\author{
C. Rasmussen ${ }^{1}$ and E. L. Gallo ${ }^{2}$ \\ ${ }^{1}$ Department of Soil, Water and Environmental Science, University of Arizona, Tucson, AZ, USA \\ ${ }^{2}$ Department of Hydrology and Water Resources, University of Arizona, Tucson, AZ, USA
}

Correspondence to: C. Rasmussen (crasmuss@ cals.arizona.edu)

Received: 24 January 2013 - Published in Hydrol. Earth Syst. Sci. Discuss.: 11 March 2013

Revised: 12 July 2013 - Accepted: 26 July 2013 - Published: 5 September 2013

\begin{abstract}
Recent work suggests that a coupled effective energy and mass transfer (EEMT) term, which includes the energy associated with effective precipitation and primary production, may serve as a robust prediction parameter of critical zone structure and function. However, the models used to estimate EEMT have been solely based on long-term climatological data with little validation using direct empirical measures of energy, water, and carbon balances. Here we compare catchment-scale EEMT estimates generated using two distinct approaches: (1) EEMT modeled using the established methodology based on estimates of monthly effective precipitation and net primary production derived from climatological data, and (2) empirical catchment-scale EEMT estimated using data from 86 catchments of the Model Parameter Estimation Experiment (MOPEX) and MOD17A3 annual net primary production (NPP) product derived from Moderate Resolution Imaging Spectroradiometer (MODIS). Results indicated positive and significant linear correspondence $\left(R^{2}=0.75 ; P<0.001\right)$ between model and empirical measures with an average root mean square error (RMSE) of $4.86 \mathrm{MJ} \mathrm{m}^{-2} \mathrm{yr}^{-1}$. Modeled EEMT values were consistently greater than empirical measures of EEMT. Empirical catchment estimates of the energy associated with effective precipitation $\left(E_{\mathrm{PPT}}\right)$ were calculated using a mass balance approach that accounts for water losses to quick surface runoff not accounted for in the climatologically modeled $E_{\mathrm{PPT}}$. Similarly, local controls on primary production such as solar radiation and nutrient limitation were not explicitly included in the climatologically based estimates of energy associated with primary production $\left(E_{\mathrm{BIO}}\right)$, whereas these were captured in the remotely sensed MODIS NPP data. These differences likely explain the greater estimate of modeled EEMT
\end{abstract}

relative to the empirical measures. There was significant positive correlation between catchment aridity and the fraction of EEMT partitioned into $E_{\mathrm{BIO}}\left(F_{\mathrm{BIO}}\right)$, with an increase in $F_{\mathrm{BIO}}$ as a fraction of the total as aridity increases and percentage of catchment woody plant cover decreases. In summary, the data indicated strong correspondence between model and empirical measures of EEMT with limited bias that agree well with other empirical measures of catchment energy and water partitioning and plant cover.

\section{Introduction}

A major challenge to the Earth sciences is understanding how energy, water, carbon, and sediment cycles interact to control process, function, and evolution of the critical zone, or the zone surface that extends from the top of the vegetative canopy down to and including groundwater (NRC, 2001). Recent studies indicate strong correlation of critical zone properties to a flux term referred to as effective energy and mass transfer (EEMT). This term represents the energy and mass transferred to the critical zone in the form of water in excess of evapotranspiration and biological production; therefore EEMT provides a measure of the energy available to perform work on the subsurface. Previous work demonstrates strong correlation of EEMT to measures of critical zone structure and function including regolith depth, chemical depletion and denudation rates, soil development and taxonomic classification, and ecosystem respiration (Pelletier and Rasmussen, 2009a; Rasmussen et al., 2005, 2011; Rasmussen and Tabor, 2007), which has been used as a predictive parameter in numerical models of

Published by Copernicus Publications on behalf of the European Geosciences Union. 
regolith depth and topographic development (Pelletier et al., 2011; Pelletier and Rasmussen, 2009a,b), and to characterize paleo-environmental conditions (Gulbranson et al., 2011; Sheldon and Tabor, 2009). Further, the EEMT framework currently forms the basis for interdisciplinary research examining the coupling of water, carbon and sediment transport across a range of critical zone systems (Chorover et al., 2011). However, to date, the application and derivation of EEMT has been purely driven with long-term average climate data, with no comparison of model estimates to empirical measures of EEMT to confirm model accuracy.

The objective of this work was to compare modeled to empirically derived values of EEMT at the catchment scale and elucidate how the relative partitioning of energy and mass transfer varies with catchment aridity. Building on the analyses of Troch et al. (2009), Brooks et al. (2011) and Rasmussen (2012), we use the Model Parameterization Experiment (MOPEX) catchment data and remotely sensed net primary productivity (NPP) data to quantify climate, vegetation and catchment water balance interactions empirically across a broad spatial and climate space.

\section{Materials and methods}

\subsection{Effective energy and mass transfer}

The EEMT framework was developed based on a rich history in the soil science literature from the initial conceptualization and semi-quantitative approaches used to describe and define soil forming factors (Dokuchaev, 1967; Jenny, 1941; Runge, 1973; Smeck et al., 1983) to later work that formalized these factors into quantitative energy terms (Volobuyev, 1964), and revisited in more recent work (Minasny et al., 2008; Phillips, 2009; Rasmussen, 2012; Rasmussen et al., 2005, 2011; Rasmussen and Tabor, 2007). This framework quantifies the drivers of critical zone evolution as the summation of energy and mass fluxes associated with soil and critical zone development, wherein development refers to chemical alteration, structure formation, and the layering, zonation, and organization of the weathered regolith. The summation of these fluxes as stated by Volobuyev (1964) and revisited by Minasny et al. (2008) is $E=w 1+w 2+b 1+b 2+e 1+e 2+g+v$, where $E$ is the energy involved in soil formation, $w 1$ the energy of physical rock weathering, $w 2$ the energy for chemical weathering, $b 1$ the energy accumulating in soil organic matter, $b 2$ the energy for soil organic matter transformation, $e 1$ the energy for evaporation from soil surface, $e 2$ the energy for transpiration, $g$ the energy losses in leaching of salts and fine materials, and $v$ the energy expended by the process of heat exchange between the soil and atmosphere (usually negligible over the timescales of soil formation).

Building on this framework, Rasmussen et al. (2011) derived this statement from the respective energy, water, carbon, and sediment balances that occur on the Earth's surface, including tectonically forced gravity-driven sediment transport, and the geochemical alteration of primary and secondary mineral phases stated as (Rasmussen et al., 2011)

$$
\begin{aligned}
E_{\mathrm{Total}}= & E_{\mathrm{ET}}+E_{\mathrm{PPT}}+E_{\mathrm{BIO}}+E_{\mathrm{ELEV}}+E_{\mathrm{GEO}}+\sum E_{\mathrm{i}} \\
& \left(\mathrm{J} \mathrm{m}^{-2} \mathrm{~s}^{-1}\right),
\end{aligned}
$$

where $E_{\mathrm{ET}}$ is energy and mass flux associated with evapotranspiration, $E_{\mathrm{PPT}}$ heat energy associated with effective precipitation energy and mass transfer, $E_{\mathrm{BIO}}$ net primary productivity energy and mass transfer, $E_{\mathrm{ELEV}}$ potential energy associated with gravity-driven transport of sediment, $E_{\mathrm{GEO}}$ geochemical potential of chemical weathering, and $E_{\mathrm{i}}$ any other external energy and mass input such as dust, anthropogenic inputs, or the heat exchange between soil and the atmosphere. The $E_{\mathrm{ET}}$ term by far represents the largest component of $E_{\text {Total }}$ and is typically several orders of magnitude greater than the sum of the remaining energy and mass flux terms (Minasny et al., 2008). However, given that $E_{\mathrm{ET}}$ represents the transfer of water and radiant energy back to the atmosphere, it has limited potential for performing chemical or physical work on the subsurface. Equation (1) may thus be restated in terms of energy and mass transferred to the subsurface $\left(E_{\text {Subsurface }}\right)$ :

$$
\begin{aligned}
E_{\text {Subsurface }}= & E_{\mathrm{PPT}}+E_{\mathrm{BIO}}+E_{\mathrm{ELEV}}+E_{\mathrm{GEO}}+\sum E_{\mathrm{i}} \\
& \left(\mathrm{J} \mathrm{m}^{-2} \mathrm{~s}^{-1}\right) .
\end{aligned}
$$

As noted, the $E_{\mathrm{ELEV}}$ and $E_{\mathrm{GEO}}$ terms encompass the physical and chemical transfers of energy and mass associated with denudation and mineral transformation. In many Earth surface systems, the sum of these fluxes may be orders of magnitude less than the water and carbon flux terms (Phillips, 2009; Rasmussen et al., 2011). Therefore, here we focus on the sum of energy and mass transfer associated with effective precipitation and primary production, which Rasmussen et al. (2011) refer to as "effective energy and mass transfer" (EEMT), and defined as

$\mathrm{EEMT}=E_{\mathrm{PPT}}+E_{\mathrm{BIO}} \quad\left(\mathrm{Jm}^{-2} \mathrm{~s}^{-1}\right)$,

where EEMT represents the summation of energy transferred to the subsurface critical zone as the heat and mass transfer associated with effective precipitation, the water in excess of evapotranspiration $\left(E_{\mathrm{PPT}}\right)$, and chemical energy associated with reduced carbon compounds derived from primary production $\left(E_{\mathrm{BIO}}\right)$.

The components of modeled EEMT estimates (Eq. 3) have units of $\mathrm{J} \mathrm{m}^{-2} \mathrm{~s}^{-1}$, or $\mathrm{W} \mathrm{m}^{-2}$, and may be calculated using traditional monthly water balance techniques (e.g., Arkley, 1963) and net primary production estimates (e.g., Lieth, 1975):

$E_{\mathrm{PPT}}=F \cdot c_{\mathrm{w}} \cdot \Delta T \quad\left(\mathrm{Jm}^{-2} \mathrm{~s}^{-1}\right)$, 
where $F$ is mass flux of water available to move into and through the subsurface $\left[\mathrm{kg} \mathrm{m}^{-2} \mathrm{~s}^{-1}\right], c_{\mathrm{W}}$ the specific heat of water $\left[\mathrm{J} \mathrm{kg}^{-1} \mathrm{~K}^{-1}\right]$, and $\Delta T=T_{\text {ambient }}-T_{\text {ref }} \Delta T=$ $T_{\text {ambient }}-T_{\text {ref }}[\mathrm{K}]$ with $T_{\text {ambient }}$ the ambient temperature at time of water flux and $T_{\text {ref }}$ set at $273.15 \mathrm{~K}$; and

$$
E_{\mathrm{BIO}}=\mathrm{NPP} \cdot h_{\mathrm{BIO}}\left(\mathrm{J} \mathrm{m}^{-2} \mathrm{~s}^{-1}\right)
$$

where NPP is mass flux of carbon as net primary production $\left[\mathrm{kg} \mathrm{m}^{-2} \mathrm{~s}^{-1}\right.$ ], and $h_{\mathrm{BIO}}$ the specific biomass enthalpy $\left[\mathrm{J} \mathrm{kg}^{-1}\right]$ fixed at a value of $22 \times 10^{6} \mathrm{~J} \mathrm{~kg}^{-1}$.

\subsection{Modeled effective energy and mass transfer}

Previous applications of the EEMT framework (Chorover et al., 2011; Pelletier and Rasmussen, 2009a; Rasmussen, 2012; Rasmussen et al., 2005, 2011; Rasmussen and Tabor, 2007; Sheldon and Tabor, 2009) have largely focused on using relatively easy to obtain annual and monthly precipitation and temperature data to calculate local water and energy balance to derive the components needed for $E_{\mathrm{PPT}}$ and $E_{\mathrm{BIO}}$. Specifically, for $E_{\mathrm{PPT}}$ the $F$ term is approximated using effective precipitation: $P_{\text {eff }}=$ PPT - PET $\left[\mathrm{kg} \mathrm{m}^{-2} \mathrm{~s}^{-1}\right]$, where PET is potential evapotranspiration calculated following Thornthwaite and Mather (1957). The net primary production (NPP) term is calculated using a modified form of the sigmoid equation of Lieth (1975) relating NPP to mean annual temperature: $\mathrm{NPP}=3000\left[1+e^{(1.315-0.119 T)}\right]^{-1}\left[\mathrm{~g} \mathrm{~m}^{-2} \mathrm{yr}^{-1}\right]$. Using this equation, NPP is calculated at monthly time steps for all months of PPT $>$ PET, and scaled to a monthly time step based on each month's percentage of one year (i.e., days ${ }_{\text {month }} /$ days $\left._{\text {year }}\right)$. Here the energy model components $\left(E_{\mathrm{PPT}}\right.$ and $\left.E_{\mathrm{BIO}}\right)$ calculated using this approach will be termed $E_{\mathrm{PPT} \text {-MODEL }}$ and $E_{\mathrm{BIO}-\mathrm{MODEL}}$ and their sum referred to as $\mathrm{EEMT}_{\mathrm{MODEL}}$.

\subsection{Empirical effective energy and mass transfer}

To meet this work's objective of comparing EEMT MODEL $_{2}$ to empirical EEMT estimates (referred to herein as EEMT $_{\text {MODIS-MOPEX), we used a subset of } 86 \text { catchments }}$ from the MOPEX database (data available at http://www. nws.noaa.gov/oh/mopex) spanning the time period from 2000 to 2009 following the analyses of Troch et al. (2009) and Brooks et al. (2011) to estimate $E_{\mathrm{PPT}}\left(E_{\mathrm{PPT}-\mathrm{MOPEX}}\right)$ and used MODIS data for the same 86 catchments to estimate $E_{\mathrm{BIO}}\left(E_{\mathrm{BIO}-\mathrm{MODIS}}\right)$. The selected catchments span a broad climate space with substantial variation in water availability and vegetation cover (Duan et al., 2006). The catchments average $3477 \mathrm{~km}^{2}$ in size, ranging from 134 to $10329 \mathrm{~km}^{2}$; annual precipitation ranges from $\sim 650$ to $1800 \mathrm{~mm} \mathrm{yr}^{-1}$, and mean annual temperature spans 10 to $22^{\circ} \mathrm{C}$. Additionally, the catchments exhibit minimal snow storage to avoid issues of winter-to-spring water carryover or snow water loss to sublimation (Brooks et al., 2011).
Empirical $E_{\text {PPT }}$ was estimated from monthly MOPEX precipitation, temperature and discharge data using a catchment balance approach (L’vovich, 1979):

$W=\mathrm{PPT}-\mathrm{SR}=\mathrm{ET}+F+\mathrm{BIO}\left(\mathrm{kgm}^{-2} \mathrm{~s}^{-1}\right)$,

where $W$ is subsurface or catchment wetting, PPT precipitation, SR quick runoff, or the immediate increase in surface discharge due to rainfall, representing water that is not available to do work on the system, ET the mass of water returned to the atmosphere by evapotranspiration, $F$ the base flow and equivalent to the fraction of precipitation available to flux through the soil and participating in weathering processes and solute transport, and BIO the mass of water incorporated into biomass via primary production. The mass flux of water associated with evapotranspiration was derived from catchment estimates of actual evapotranspiration (AET) calculated as the balance of precipitation and discharge: $\mathrm{AET}=\mathrm{PPT}-Q\left(\mathrm{~kg} \mathrm{~m}^{-2} \mathrm{~s}^{-1}\right)$. Discharge $(Q)$ was partitioned to SR and $F$ based on the analysis of Brooks et al. (2011). The $E_{\mathrm{PPT}}$ term was then calculated using catchment base flow and air temperature as $E_{\text {PPT-MOPEX }}=F \cdot c_{\mathrm{w}} \cdot \Delta T$. Values of $E_{\mathrm{PPT}}$ were calculated on a monthly basis and summed to provide an annual measure of $E_{\mathrm{PPT}}$, termed $E_{\mathrm{PPT}-\mathrm{MOPEX}}$.

Annual net primary production for each MOPEX catchment was taken from the MODIS data product MOD17A3 for the period 2000-2009 (Zhao and Running, 2010) (data available in GeoTIFF format from the Numerical Terradynamic Simulation Group at ftp://ftp.ntsg.umt.edu/pub/ MODIS/Mirror/MOD17_Science2010/MOD17A3/Geotiff).

The MODA17 data product provides annual estimates of NPP $\left[\mathrm{g} \mathrm{C} \mathrm{m}^{-2} \mathrm{yr}^{-1}\right.$ ] at $1 \mathrm{~km}$ pixel resolution. The algorithm for NPP includes parameters for shortwave downward solar radiation, the fraction of photosynthetically active radiation adsorbed by plants, vapor pressure deficit, temperature, light use efficiency, and maintenance respiration (Running et al., 2004). After download, the MODIS NPP data were subset to exclude any areas of no data including surface water bodies and any urban/developed areas within the MOPEX catchments. Annual $E_{\mathrm{BIO}-\mathrm{MODIS}}$ was calculated as in Eq. (4): $E_{\mathrm{BIO}-\mathrm{MODIS}}=\mathrm{NPP} \cdot h_{\mathrm{BIO}}$.

The empirical energy balance estimates calculated using the MOPEX and MODIS data were summed to provide a "measured EEMT" where

$$
\begin{aligned}
\text { EEMT }_{\text {MOPEX-MODIS }}= & E_{\text {PPT-MOPEX }}+E_{\text {BIO-MODIS }} \\
& \left(\mathrm{J} \mathrm{m}^{-2} \mathrm{~s}^{-1}\right) .
\end{aligned}
$$

\subsection{Catchment energy partitioning}

The values of EEMT ${ }_{\text {MODEL }}, E_{\mathrm{PPT}-\mathrm{MODEL}}$ and $E_{\mathrm{BIO}-\mathrm{MODEL}}$ were compared to EEMT MOPEX-MODIS, $_{\text {PPT-MOPEX and }}$ $E_{\mathrm{BIO}-\mathrm{MODIS}}$ to check the validity of the model approach 

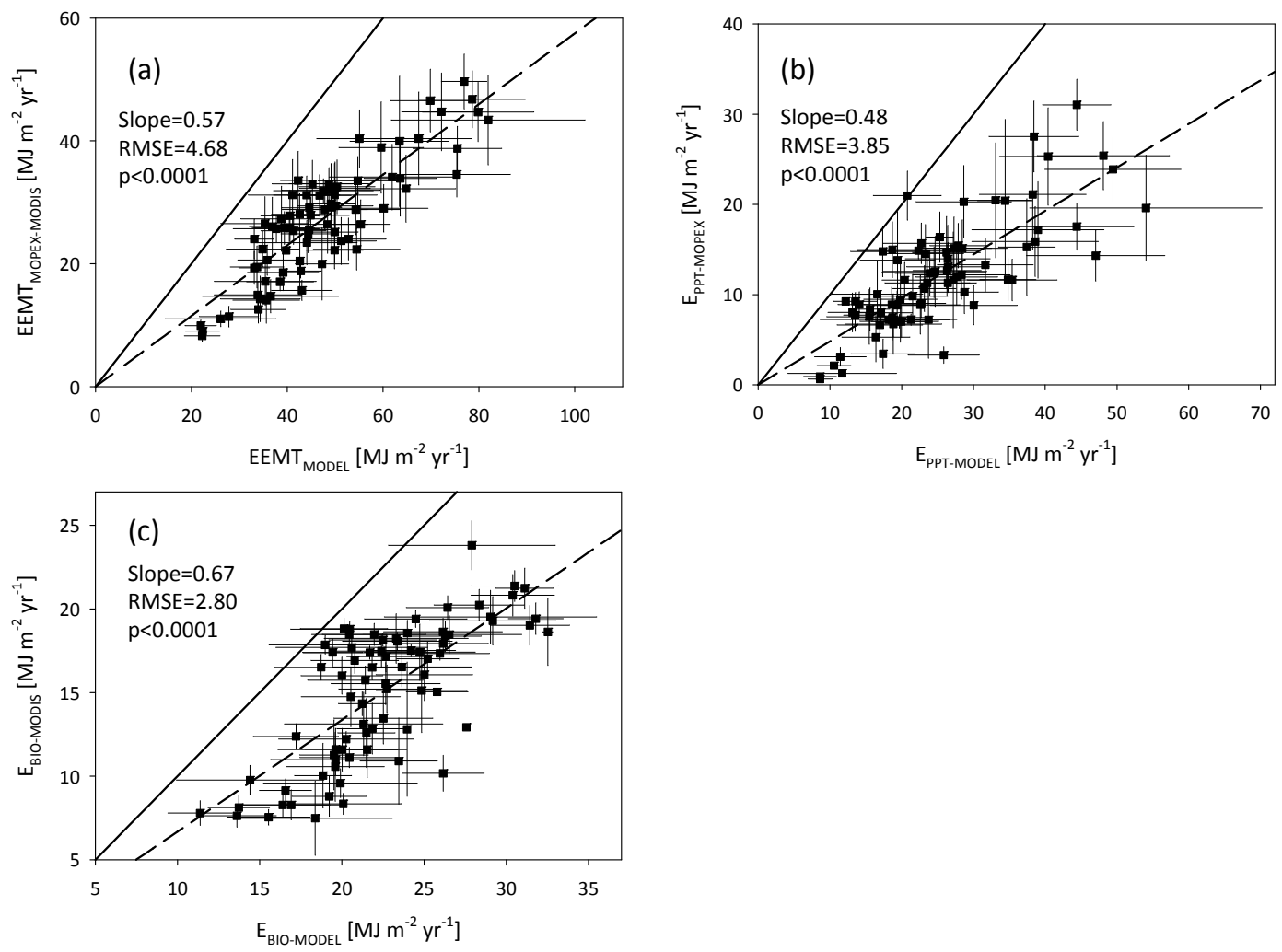

Fig. 1. The relationship between (a) effective energy and mass transfer (EEMT) quantified using MOPEX baseflow and MODIS net primary production data (EEMT MOPEX-MODIS) relative to modeled EEMT (EEMT $_{\text {MODEL }}$ ), (b) water transferred heat energy input derived from MOPEX baseflow data $\left(E_{\text {PPT-MOPEX }}\right)$ and modeled heat transfer $\left(E_{\text {PPT-MODEL }}\right)$, and $(\mathbf{c})$ biological chemical energy input derived from MODIS net primary production ( $\left.E_{\mathrm{BIO}-\mathrm{MODIS}}\right)$ and modeled primary production $\left(E_{\mathrm{BIO}-\mathrm{MODEL}}\right)$. The $1: 1$ relationship is noted as solid lines, and the dashed lines represent best fit linear functions fit with an intercept of zero. Error bars are standard errors of the annual means over the period of record.

and values. In addition, the relative partitioning of EEMT to

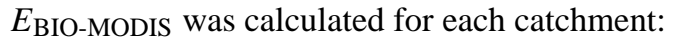

$F_{\mathrm{BIO}}=\frac{E_{\text {BIO-MODIS }}}{\text { EEMT }_{\text {MOPEX-MODIS }}}$.

The $F_{\mathrm{BIO}}$ term was compared to the aridity index, or the ratio of potential evapotranspiration to precipitation $\left(\right.$ PET $\left._{\text {MOPEX }}\right)$ as a more traditional measure of water availability (Budyko, 1974). Further, we compared $F_{\mathrm{BIO}}$ to the fraction of catchment woody plant as derived from the 2001 National Land Cover Database (NLCD, Homer et al., 2007), available for download from the Multi-Resolution Land Characteristics Consortium (http://www.mrlc.gov/nlcd2001.php). Greater detail and data summary is included in Brooks et al. (2011).

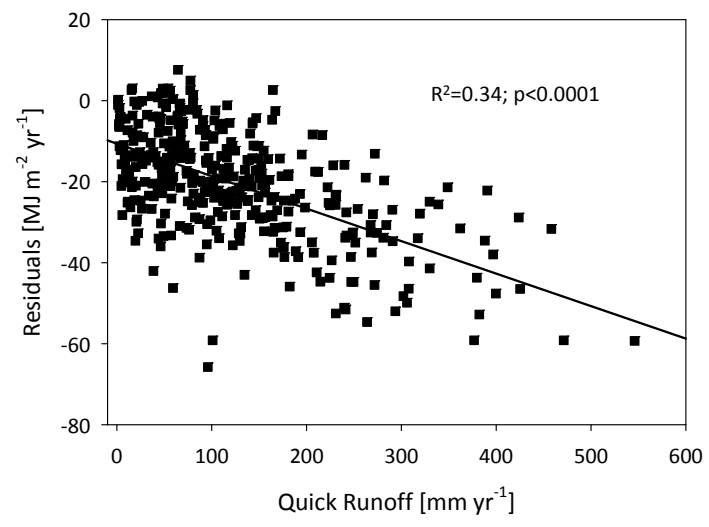

Fig. 2. The relationship between the residuals of the $1: 1$ fit between

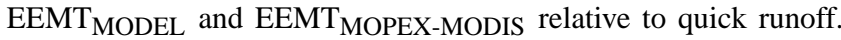
Data include all observation years. The solid line is the best fit linear regression. 

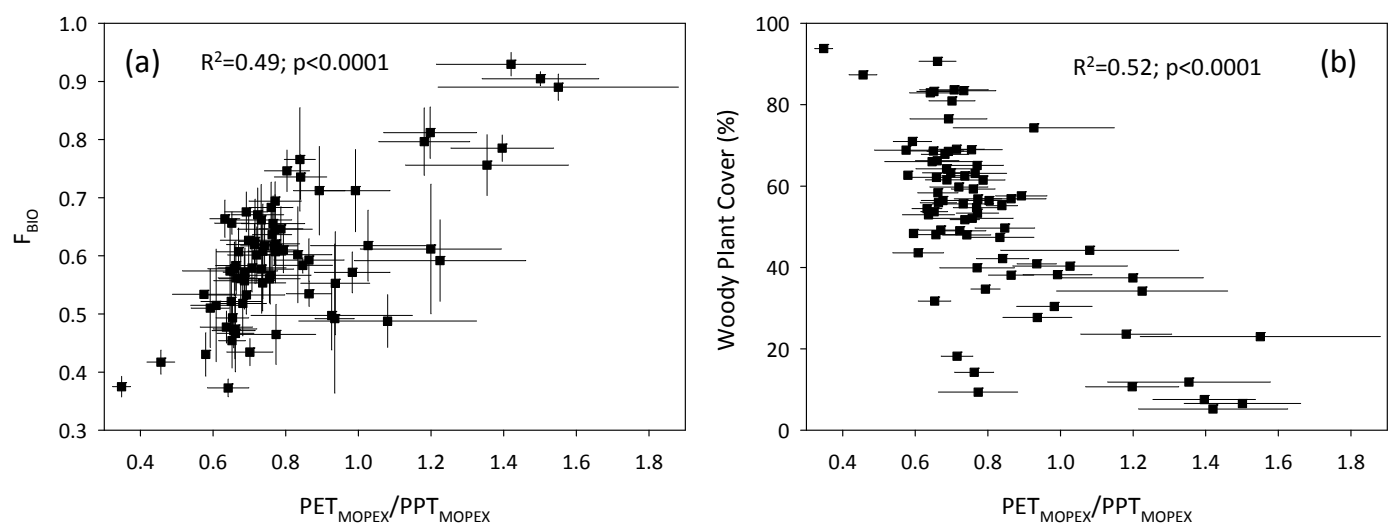

Fig. 3. The relationship between (a) the fraction of effective energy and mass transfer (EEMT) derived from biological energy input $\left(F_{\mathrm{BIO}}\right)$ and (b) the catchment percent woody plant cover relative to the ratio of potential evapotranspiration to precipitation (PET / PPT). Error bars in (a) are standard errors of the annual means over the period of record; error bars in (b) are standard errors of the annual means over the period of record for PET/PPT. Woody plant cover was taken from 2001 NLCD database, which does not represent annual variation in percent woody plant cover. As such, error bars were not included for percent woody plant cover.

\section{Results and discussion}

\subsection{Model and empirical data comparison}

Modeled values of EEMT, $E_{\mathrm{PPT}}$ and $E_{\mathrm{BIO}}$ were all linearly and significantly $(p<0.0001)$ correlated with their respective empirical values derived from the MOPEX and MODIS datasets with an average RMSE of 4.68, 3.85, and $2.80 \mathrm{MJ} \mathrm{m}^{-2} \mathrm{yr}^{-1}$, respectively (Fig. 1). The linear regressions indicated that EEMT ${ }_{\text {MOPEX-MODIS, }} E_{\text {PPT-MOPEX and }}$ $E_{\mathrm{BIO}-\mathrm{MODIS}}$ were, on average, 0.57 to 0.48 to 0.67 times less than EEMT $\mathrm{MODEL}_{\mathrm{L}}, E_{\mathrm{PPT}-\mathrm{MODEL}}$ and $E_{\mathrm{BIO}-\mathrm{MODEL}}$. The strong linear correlations and relatively low RMSE indicate that while the magnitude of EEMT MODEL in previous work relating EEMT to critical zone properties and process may be overestimated (Chorover et al., 2011; Pelletier and Rasmussen, 2009a; Rasmussen, 2012; Rasmussen et al., 2005, 2011; Rasmussen and Tabor, 2007; Sheldon and Tabor, 2009), the overall trends in critical zone properties relative to EEMT remain valid.

The overprediction of $E_{\mathrm{PPT} \text {-MODEL }}$ relative to $E_{\mathrm{PPT}-\mathrm{MOPEX}}$ is a function of the catchment water balance approach applied to the MOPEX data that accounts for losses of precipitation to quick runoff, water that would otherwise be partitioned to base flow and $E_{\text {PPT }}$. In the selected MOPEX catchments, quick runoff increases linearly and significantly with increasing precipitation, with an average of $10 \%$ of precipitation partitioned to quick runoff and a range of $\sim 0.5$ to $30 \%$. Analysis of the residuals of EEMT MODEL $_{\text {and }}$ $E_{\text {PPT-MODEL }}$ relative to an ideal $1: 1$ fit indicates that quick runoff accounts for $\sim 35 \%(p<0.0001)$ of the variance in both EEMT MODEL $_{\text {and }} E_{\mathrm{PPT}-M O D E L}$ residuals, and data indicate significant decrease in the model residuals with greater quick runoff (Fig. 2). The monthly water balance used for EEMT $_{\text {MODEL does not account for quick runoff, the fraction }}$ of rainfall that leaves the catchment too quickly to perform work, and thus overpredicts the water available for base flow and $E_{\mathrm{PPT}}$. Additionally, the catchment water balance employed here assumes that the change in storage may be neglected over annual timescales; however, it is possible there is unaccounted storage of water within the catchments that would lead to an underestimation of $E_{\text {PPT-MOPEX. }}$

The modeled $E_{\mathrm{BIO}}$ is based on the temperature of those months where PPT $>$ PET. This model does not account for local-scale variation in photosynthetically active radiation, water redistribution, and nutrient limitation, all factors that limit primary production under natural conditions (Melillo et al., 1993; Newman et al., 2006). The algorithm for calculating NPP MODIS considers many of these limitations either directly or indirectly (Running et al., 2004). Thus the overprediction of $E_{\text {BIO-MODEL }}$ relative to $E_{\text {BIO-MODIS }}$ is likely a function of the lack of parameterization and mechanism in the $E_{\mathrm{BIO}-\mathrm{MODEL}}$ framework.

\subsection{Energy and mass partitioning}

The relative partitioning of EEMT MOPEX-MODIS to $_{\text {M }}$

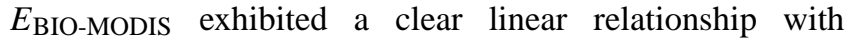
the aridity index (Fig. 3a). Values of $F_{\text {BIO }}$ ranged from 0.37 to 0.93 (Fig. 3a), indicating that net primary production accounts for as much as $93 \%$ of the total energy water and carbon flux into the critical zone, particularly in systems with potential evapotranspiration greater than precipitation. The percentage of catchment woody plant cover also decreased with increasing aridity (Fig. 3b). Correspondingly, the

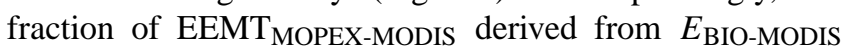
significantly decreased with increasing woody plant cover $\left(R^{2}=0.31 ; p<0.0001\right)$. These data confirm previous results that "low" EEMT systems are typically water limited and dominated by primary production as the principle 
component of EEMT (e.g., Rasmussen, 2012). The "high" EEMT systems, while exhibiting the greatest woody plant cover, are principally dominated by energy associated with $E_{\mathrm{PPT}}$ despite relatively greater rates of primary production. In the water-limited systems, any water available in excess of evapotranspiration is partitioned to primary production, with minimal water remaining for base flow and $E_{\mathrm{PPT}}$. Thus the systems express low EEMT values dominated by $E_{\mathrm{BIO}}$. In contrast, the wet, energy-limited systems have substantial water in excess of evapotranspiration, facilitating greater base flow and $E_{\mathrm{PPT}}$, relatively high EEMT, and greater subsurface development.

\section{Summary}

The comparison of simple monthly water balance-based estimates of EEMT to direct empirical measures of EEMT at the catchment scale indicates a strong positive, linear correlation between model and measured values with an average bias of $4.68 \mathrm{MJ} \mathrm{m}^{-2} \mathrm{yr}^{-1}$. The empirical measures thus confirm previously published trends in EEMT and the relationship of EEMT to various measures of critical zone structure and function. The monthly water balance model consistently overpredicted both the water and biological components of EEMT due to a lack of accounting for precipitation losses to quick runoff in the water component and the simplicity of modeled net primary production that does not account for local water redistribution, terrain-controlled variation in radiation and nutrient limitations. The relative partitioning of EEMT to water and biological energy and mass transfers varied consistently with aridity index and woody plant cover.

Acknowledgements. This work was supported by a grant from the US National Science Foundation NSF EAR \#0724958.

Edited by: S. Archfield

\section{References}

Arkley, R. J.: Calculation of carbonate and water movement in soil from climate data, Soil Sci., 96, 239-248, 1963.

Brooks, P. D., Troch, P. A., Durcik, M., Gallo, E., and Schlegel, M.: Quantifying regional scale ecosystem response to changes in precipitation: Not all rain is created equal, Water Resour. Res., 47, W00J08, doi:10.1029/2010WR009762, 2011.

Budyko, M. I.: Climate and Life, Academic, San Diego, CA, 508 pp., 1974.

Chorover, J., Troch, P. A., Rasmussen, C., Brooks, P. D., Pelletier, J. D., Breshears, D. D., Huxman, T. E., Kurc, S. A., Lohse, K. A., McIntosh, J. C., Meixner, T., Schaap, M. G., Litvak, M. E., Perdrial, J., Harpold, A., and Durcik, M.: How Water, Carbon, and Energy Drive Critical Zone Evolution: The Jemez-Santa Catalina Critical Zone Observatory, Vadose Zone J., 10, 884-899, 2011.
Dokuchaev, V. V.: Selected works of V. V. Dokuchaev, Israel Program for Scientific Translations, available from the US Dept. of Commerce, Clearinghouse for Federal Scientific and Technical Information, Jerusalem, Springfield, Va., 1967.

Duan, Q., Schaake, J., Andreassian, V., Franks, S., Goteti, G., Gupta, H. V., Gusev, Y. M., Habets, F., Hall, A., Hay, L., Hogue, T., Huang, M., Leavesley, G., Liang, X., Nasonova, O. N., Noilhan, J., Oudin, L., Sorooshian, S., Wagener, T., and Wood, E. F.: Model Parameter Estimation Experiment (MOPEX): An overview of science strategy and major results from the second and third workshops, J. Hydrol., 320, 3-17, doi:10.1016/j.jhydrol.2005.07.031, 2006.

Gulbranson, E. L., Montanez, I. P., and Tabor, N. J.: A Proxy for Humidity and Floral Province from Paleosols, J. Geol., 119, 559573, doi:10.1086/661975, 2011.

Homer, C., Dewitz, J., Fry, J., Coan, M., Hossain, N., Larson, C., Herold, N., McKerrow, A., VanDriel, J. N., and Wickham, J.: Completion of the 2001 National Land Cover Database for the Conterminous United States, Photogramm. Eng. Rem. S., 73, 337-341, 2007.

Jenny, H.: Factors of soil formation; a system of quantitative pedology, 1st Edn., McGraw-Hill book company, Inc., New York, London, xii, 281 pp., 1941.

Lieth, H.: Primary production of the major vegetation units of the world, in: Primary Productivity of the Biosphere, edited by: Leith, H. and Whittaker, R. H., Springer-Verlag, New York, NY, 203-215, 1975.

L'vovich, M. I.: World water resources and their future, Original in Russian, English translation American Geophysical Union, Washington, D.C., 1979.

Melillo, J., McGuire, A. D., Kicklighter, D., Moore, B., Vorosmarty, C. J., and Schloss, A. L.: Global climate change and terrestrial net primary productivity, Nature, 363, 234-240, 1993.

Minasny, B., McBratney, A. B., and Salvador-Blanes, S.: Quantitative models for pedogenesis - A review, Geoderma, 144, 140157, 2008.

Newman, B. D., Wilcox, B. P., Archer, S. R., Breshears, D. D., Dahm, C. N., Duffy, C. J., McDowell, N. G., Phillips, F. M., Scanlon, B. R., and Vivoni, E. R.: Ecohydrology of waterlimited environments: A scientific vision, Water Resour. Res., 42, W06302, doi:10.1029/2005wr004141, 2006.

NRC: Basic Research Opportunities in Earth Sciences, National Research Council, Washington, D.C., 2001.

Pelletier, J. D. and Rasmussen, C.: Quantifying the climatic and tectonic controls on hillslope steepness and erosion rate, Lithosphere, 1, 73-80, 2009a.

Pelletier, J. D. and Rasmussen, C.: Geomorphically based predictive mapping of soil thickness in upland watersheds, Water Resour. Res., 45, W09417, doi:10.1029/2008WR0073, 2009b.

Pelletier, J. D., McGuire, L. A., Ash, J. L., Engelder, T. M., Hill, L. E., Leroy, K. W., Orem, C. A., Rosenthal, S. W., Trees, M. A., Rasmussen, C., and Chorover, J.: Calibration and testing of upland hillslope evolution models in a dated landscape: Banco Bonito, New Mexico, USA, J. Geophys. Res., 116, F04004, doi:10.1029/2011JF001976, 2011.

Phillips, J. D.: Biological Energy in Landscape Evolution, Am. J. Sci., 309, 271-289, 2009. 
Rasmussen, C.: Thermodynamic constraints on effective energy and mass transfer and catchment function, Hydrol. Earth Syst. Sci., 16, 725-739, doi:10.5194/hess-16-725-2012, 2012.

Rasmussen, C. and Tabor, N. J.: Applying a quantitative pedogenic energy model across a range of environmental gradients, Soil Sci. Soc. Am. J., 71, 1719-1729, 2007.

Rasmussen, C., Southard, R. J., and Horwath, W. R.: Modeling energy inputs to predict pedogenic environments using regional environmental databases, Soil Sci. Soc. Am. J., 69, 1266-1274, 2005.

Rasmussen, C., Troch, P. A., Chorover, J., Brooks, P., Pelletier, J., and Huxman, T. E.: An open system framework for integrating critical zone structure and function, Biogeochemistry, 102, 1529, doi:10.1007/s10533-010-9476-8, 2011.

Runge, E. C. A.: Soil development sequences and energy models, Soil Sci., 115, 183-193, 1973.

Running, S. W., Nemani, R. R., Heinsch, F. A., Zhao, M. S., Reeves, M., and Hashimoto, H.: A continuous satellite-derived measure of global terrestrial primary production, Bioscience, 54, 547560,2004

Sheldon, N. D. and Tabor, N. J.: Quantitative paleoenvironmental and paleoclimatic reconstruction using paleosols, Earth-Sci. Rev., 95, 1-52, doi:10.1016/j.earscirev.2009.03.004, 2009.
Smeck, N. E., Runge, E. C. A., and Mackintosh, E. E.: Dynamics and genetic modeling of soil systems, in: Pedogenesis and Soil Taxonomy, edited by: Wilding, L. P., Smeck, N. E., and Hall, G. F., Elsevier, New York, 51-81, 1983.

Thornthwaite, C. W. and Mather, J. R.: Instructions and tables for computing potential evapotranspiration and the water balance by: C. W. Thornthwaite, J. R. Mather, D. B. Carter, Climatology, 10, 183-311, 1957.

Troch, P. A., Martinez, G. F., Pauwels, V. R. N., Durcik, M., Sivapalan, M., Harman, C., Brooks, P. D., Gupta, H., and Huxman, T. Climate and vegetation water use efficiency at catchment scales, Hydrol. Process., 23, 2409-2414, doi:10.1002/Hyp.7358, 2009.

Volobuyev, V. R.: Ecology of Soils, Academy of Sciences of the Azerbaidzn SSR, Institute of Soil Science and Agrochemistry, Israel Program for Scientific Translations, Jersualem, 1964.

Zhao, M. S. and Running, S. W.: Drought-Induced Reduction in Global Terrestrial Net Primary Production from 2000 Through 2009, Science, 329, 940-943, doi:10.1126/science.1192666, 2010 . 